ARTICLE

DOI: $10.1038 / s 41467-018-04095-x$

\title{
Sulfenate anions as organocatalysts for benzylic chloromethyl coupling polymerization via $\mathrm{C}=\mathrm{C}$ bond formation
}

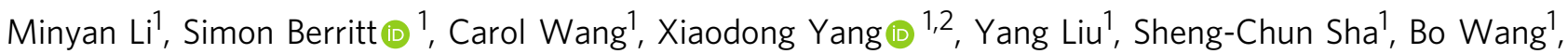
Rui Wang ${ }^{3}$, Xuyu Gao ${ }^{4}$, Zhanyong $\mathrm{Li}^{5}$, Xinyuan Fan ${ }^{3}$, Youtian Tao ${ }^{4}$ \& Patrick J. Walsh (1) ${ }^{1,3}$

Organocatalytic polymerization reactions have a number of advantages over their metal-catalyzed counterparts, including environmental friendliness, ease of catalyst synthesis and storage, and alternative reaction pathways. Here we introduce an organocatalytic polymerization method called benzylic chloromethyl-coupling polymerization (BCCP). BCCP is catalyzed by organocatalysts not previously employed in polymerization processes (sulfenate anions), which are generated from bench-stable sulfoxide precatalysts. The sulfenate anion promotes an umpolung polycondensation via step-growth propagation cycles involving sulfoxide intermediates. BCCP represents an example of an organocatalyst that links monomers by $\mathrm{C}=\mathrm{C}$ double bond formation and offers transition metal-free access to a wide variety of polymers that cannot be synthesized by traditional precursor routes.

\footnotetext{
${ }^{1}$ Roy and Diana Vagelos Laboratories, Penn/Merck Laboratory for High-Throughput Experimentation, Department of Chemistry, University of Pennsylvania, 231 South 34th Street, Philadelphia, Pennsylvania 19104, USA. ${ }^{2}$ Key Laboratory of Medicinal Chemistry for Natural Resources, Ministry of Education and Yunnan Province, School of Chemical Science and Technology, Yunnan University, Kunming 650091, P. R. China. ${ }^{3}$ Institute of Advanced Synthesis, School of Chemistry and Molecular Engineering, Jiangsu National Synergetic Innovation Center for Advanced Materials, Nanjing Tech University, 30 South Puzhu Road, Nanjing 211816, China. ${ }^{4}$ Key Laboratory of Flexible Electronics (KLOFE) and Institute of Advanced Materials (IAM), Nanjing Tech University, 30 South Puzhu Road, Nanjing 211816, China. ${ }^{5}$ Key Laboratory of Functional Polymer Materials, Ministry of Education, Institute of Polymer Chemistry, Nankai University,

Tianjin 300071, China. Correspondence and requests for materials should be addressed to P.J.W. (email: pwalsh@sas.upenn.edu)
} 
nnovations in polymer chemistry and materials science often have their genesis in the introduction of small molecule catalysts $^{1,2}$. This is particularly true in the developing field of organocatalytic polymerization chemistry., ${ }^{3,4}$ Organocatalytic polymerization reactions have a number of advantages over their metal-catalyzed counterparts, including environmental friendliness, reduced toxicity and cost, ease of catalyst synthesis and storage, and access to alternative reaction pathways. Furthermore, organocatalysts circumvent problems caused by metal residue contamination of polymers, which can severely limit biomedical and electronic applications, and complicate polymer purification and processing ${ }^{3,4}$. The majority of organocatalytic polymerizations involve ring-opening polymerizations using cyclic esters, carbonates, ethers, siloxanes, anhydrides, and phosphoesters ${ }^{4}$.

Herein we introduce a class of organocatalytic polymerization processes termed benzylic chloromethyl-coupling polymerization (BCCP). BCCP represents the application of sulfenate anion organocatalysts to polymerization processes. The sulfenate anioncatalyzed process proceeds via an umpolung mechanism and represents a rare example of an organocatalysts that enchains monomers by $\mathrm{C}=\mathrm{C}$ bond formation ${ }^{5,6}$. Design of BCCP is validated in the context of poly $\left(m\right.$-phenylene vinylene) $\left(\mathrm{P}^{m} \mathrm{PV}\right)$ synthesis. In this study, $\mathrm{P}^{m} \mathrm{PV}$ 's with $M_{\mathrm{n}}$ as high as $17,400 \mathrm{Da}$ and with very high trans-selectivity are obtained. To demonstrate the mechanistic distinctness of BCCP, a non-conjugated polymer bearing quaternary $-\mathrm{C}\left(\mathrm{CF}_{3}\right)_{2}$ spacers between stilbene units in the polymer backbone is synthesized. Moreover, two alternating co-polymers as representatives of poly[(1,3-phenylene vinylene)alt-arene $] s$ and poly[(1,3-phenylene vinylene)-alt-(1,4-phenylene vinylene $)]\left(\mathrm{P}^{m} \mathrm{PV}^{p} \mathrm{PV}\right) \mathrm{s}$ are synthesized. Nuclear magnetic resonance (NMR) spectra, thermal, photophysical, electrochemical, and charge transport properties of the above mentioned co-polymers are characterized. The polymers reported herein cannot be prepared by classic precursor routes (Gilch, Wesling, and Vanderzande methods).

\section{Results}

Design of the BCCP. Sulfenate anions ( $\mathrm{ArSO}^{-}$) are highly reactive intermediates in biological chemistry and in organic reactions ${ }^{7-10}$. We recently disclosed that sulfenate anions can act as organocatalysts and reported their ability to catalytically dehydrocouple benzyl halides under basic conditions to yield trans-stilbenes (Fig. 1a) ${ }^{11}$ and their application to catalytic cross-coupling of benzyl chlorides with benzaldehyde derivatives to produce diarylacetylenes ${ }^{12}$. The efficiency of sulfenate anion catalysts in these reactions, and their high selectivity for formation of trans-stilbenes, inspired us to explore their potential

a

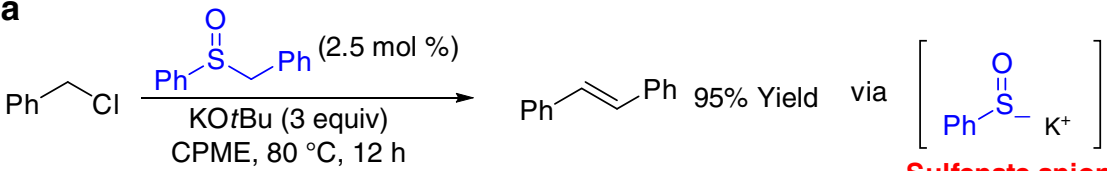

b

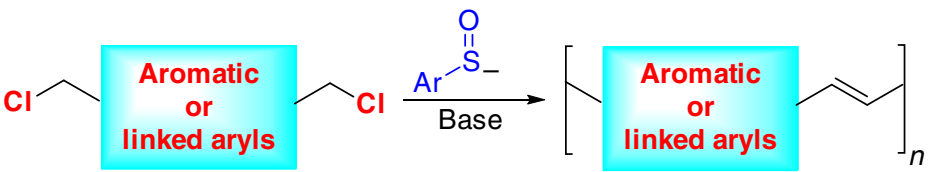

C $\operatorname{Poly}(m$-phenylene vinylene $)$

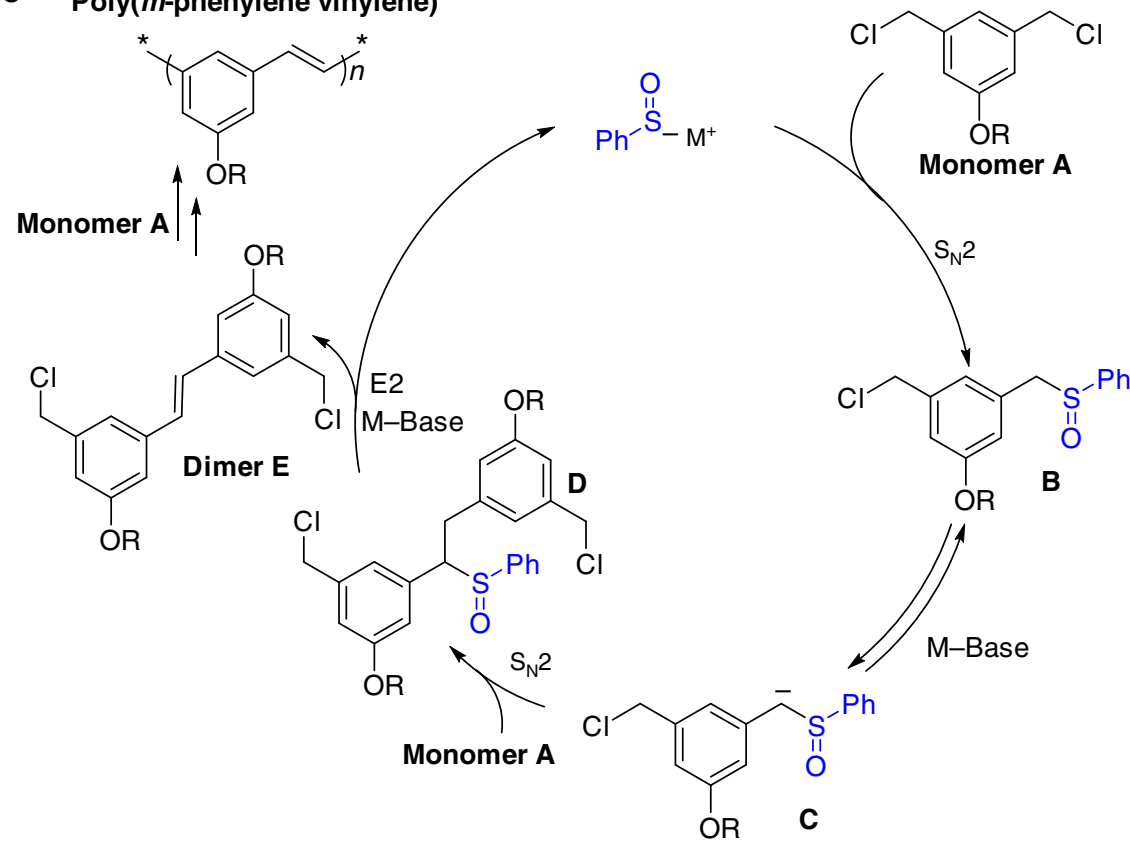

Fig. 1 Sulfenate anion-catalyzed reactions. a Dehydrocoupling of benzyl chlorides to produce stilbenes. b Generic representation of the benzylic chloromethyl-coupling polymerization (BCCP), where the blue box represents an aromatic system or tethered aromatic rings. c Fundamental steps in the organocatalytic BCCP 
in polymerization reactions. We hypothesized that substrates bearing two benzylic chloromethyl groups would be suitable monomers for polymerization. The benzylic chloromethyl substituents could be located on the same aromatic system or on different aromatic rings separated by linking groups, as represented in Fig. $1 \mathrm{~b}$.

Based on this hypothesis, we designed the 1,3-bis(chloromethyl)benzene monomer A (Fig. 1c). We envisioned that the sulfenate anion would react with monomer $A$ via an $S_{N} 2$ reaction to generate sulfoxide $\mathbf{B}$. In the presence of base, sulfoxide $\mathbf{B}$ is reversibly deprotonated to generate carbanion $\mathbf{C}$. Anion $\mathbf{C}$ is a reactive nucleophile and undergoes $\mathrm{S}_{\mathrm{N}} 2$ with monomer $\mathbf{A}$ to form the first $\mathrm{C}-\mathrm{C}$ bond. Base promoted E2 elimination of intermediate $\mathbf{D}$ provides dimer $\mathbf{E}$ and liberates the sulfenate anion to further catalyze the polycondensation of $\mathbf{E}$. Notably, the product is a $\mathrm{P}^{m} \mathrm{PV}$, which is an important class of organic semiconductors with applications in optoelectronics, such as organic lightemitting diodes (OLEDs), solar cells, organic lasers, sensors, and displays ${ }^{13-18}$. Although the synthesis of PPV's has been developed, including precursor routes ${ }^{19-23}$, olefin metathesis polymerizations $^{23}$, nucleophilic condensations ${ }^{24-29}$, and crosscoupling polymerizations ${ }^{30-36}$, to the best of our knowledge this is a unique organocatalytic method for the synthesis of this important class of polymers. Moreover, $\mathrm{P}^{m} \mathrm{PV}$ is a challenging target, because meta-linkages preclude formation of quinodimethane intermediates, prohibiting classic PPV precursor routes (Gilch, Wesling and Vanderzande methods) ${ }^{33,37-40}$.

Optimization of BCCP with monomer M1. Starting from the optimized coupling of benzyl chlorides used in our stilbene synthesis (Fig. 1a) ${ }^{11}$, we selected cyclopentyl methyl ether (CPME) as solvent and $\mathrm{KO} t \mathrm{Bu}$ as base at $80^{\circ} \mathrm{C}$, to optimize the polymerization of monomer M1 (Fig. 2). A long alkyl chain was introduced onto the $\mathrm{P}^{m} \mathrm{PV}$ backbone to assure the resulting polymer P1 has good solubility in common organic solvents. Initial reactions were conducted in 24 -well plates on $10 \mu \mathrm{mol}$ scale by adapting small molecule high-throughput experimentation (HTE) ${ }^{41-48}$ techniques to polymerizations (see Supplementary Method, High-Throughput Experimentation screenings for polymerization for full details). As shown in Fig. 2a, we initially focused on air-stable benzylic sulfoxide catalysts (1-9) $\mathrm{ArSOCH}_{2} \mathrm{Ph}$ with various $\mathrm{Ar}-\mathrm{S}$ groups and one precatalyst (10) with 4 catalyst loadings $(10,7.5,5.0$, and $2.5 \mathrm{~mol} \%)$. Reactions were heated for $24 \mathrm{~h}$ at $80^{\circ} \mathrm{C}$ followed by cooling and work up by addition of $10 \mu \mathrm{L}$ of water and removal of the volatile materials. Next, $\mathrm{CHCl}_{3}$ was added to each well to dissolve the products followed by cold methanol to precipitate the solid polymer. Finally, filtration of the solid, dissolution in tetrahydrofuran (THF) and analysis by gel permeation chromatography (GPC)

Catalyst and loading screening

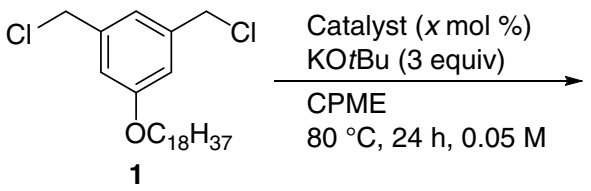

Catalyst:

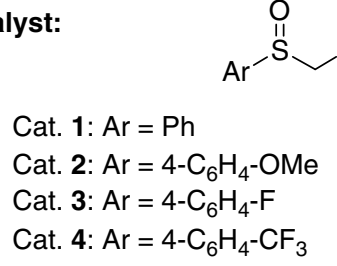

Cat. 5: $\mathrm{Ar}=$ 1-Naph

Cat. 6: $\mathrm{Ar}=2-\mathrm{Naph}$

Cat. 7: $\mathrm{Ar}=2-\mathrm{C}_{6} \mathrm{H}_{4}-\mathrm{Me}$

Cat. 8: $\mathrm{Ar}=$ 3-Pyridyl

Cat. 9: Ar = 4-Pyridyl

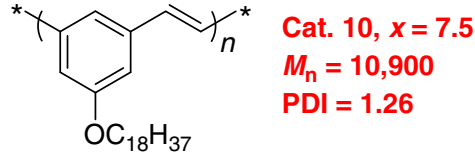<smiles>O=S([Al])CCc1ccccc1</smiles>

Cat. 10

Loading: $x=10,7.5,5,2.5 \mathrm{~mol} \%$

b Base screening

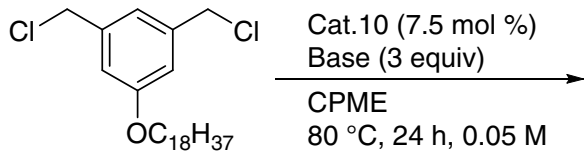

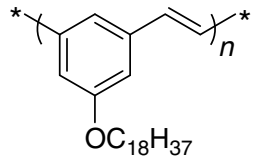

$\mathrm{NaN}\left(\mathrm{SiMe}_{3}\right)_{2}$

$M_{\mathrm{n}}=10,200$

$\mathrm{PDI}=1.25$

Bases: $\mathrm{LiOtBu}, \mathrm{NaOtBu}, \mathrm{LiN}\left(\mathrm{SiMe}_{3}\right)_{2}, \mathrm{NaN}\left(\mathrm{SiMe}_{3}\right)_{2}$, $\mathrm{KN}\left(\mathrm{SiMe}_{3}\right)_{2}, \mathrm{NaH}, \mathrm{KH}, \mathrm{KO}\left(\mathrm{SiMe}_{3}\right)_{2}, \mathrm{KOPh}, \mathrm{NaOMe}$

C Solvent screening

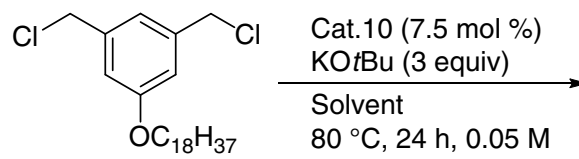

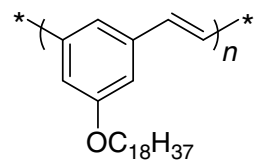

MTBE

$M_{\mathrm{n}}=13,200$

$\mathrm{PDI}=1.23$

Solvents: THF, dioxane, MTBE, toluene, DMF

Fig. 2 Optimization by HTE Screening. a Precatalysts employed leading to sulfoxide $\mathbf{1 0}$ for further studies. b Additional base screen indicated that NaN $\left(\mathrm{SiMe}_{3}\right)_{2}\left(M_{\mathrm{n}}=10,200\right)$ gave the best results, but lower than $\mathrm{KOtBu}\left(M_{\mathrm{n}}=10,900\right)$ of panel $\mathbf{a}$. $\mathbf{c}$ Additional solvent screen, wherein MTBE gave the best results $\left(M_{n}=13,200\right)$ higher than CPME of panel a. See Supplementary Table 3 for all results 


\begin{tabular}{|c|c|c|c|c|c|c|}
\hline & $\mathrm{OC}_{18} \mathrm{H}_{37}$ & \multicolumn{3}{|c|}{$\begin{array}{c}\text { Cat.10 }(7.5 \text { mol \%) } \\
\text { KOtBu (x equiv) } \\
\text { Solvent } \\
80^{\circ} \mathrm{C}, 24 \text { h, Conc. }\end{array}$} & \multicolumn{2}{|c|}{$\begin{array}{c}\mathrm{OC}_{18} \mathrm{H}_{37} \\
\mathbf{P 1}\end{array}$} \\
\hline Entry & Solvent & $\mathbf{x}=$ & $\begin{array}{l}\text { Conc. } \\
\text { (M) }\end{array}$ & $\begin{array}{l}\text { Yield } \\
(\%) \\
\end{array}$ & $M_{n}(\mathrm{Da})$ & PDI \\
\hline 1 & CPME & 3 & 0.05 & 91 & 10,400 & 1.28 \\
\hline 2 & MTBE & 3 & 0.05 & 69 & 13,600 & 1.21 \\
\hline 3 & CPME & 3 & 0.1 & 86 & 11,200 & 1.26 \\
\hline 4 & CPME & 3 & 0.2 & 73 & 12,200 & 1.29 \\
\hline 5 & MTBE & 3 & 0.1 & 72 & 15,300 & 1.41 \\
\hline 6 & MTBE & 3 & 0.2 & 71 & 17,400 & 1.42 \\
\hline 7 & CPME & 4 & 0.05 & 92 & 10,600 & 1.23 \\
\hline 8 & CPME & 5 & 0.05 & 92 & 10,300 & 1.22 \\
\hline 9 & CPME & 6 & 0.05 & 91 & 10,200 & 1.22 \\
\hline
\end{tabular}

Reactions were conducted using monomer M1 $(0.1 \mathrm{mmol})$. The products were obtained by reprecipitation from $\mathrm{CHCl}_{3}-\mathrm{CH}_{3} \mathrm{OH}$. Polymer analysis $\left(M_{n}, \mathrm{PDI}\right)$ were estimated by GPC calibrated on polystyrene standards with THF as eluent

against polystyrene standards were performed. In this screen we observed complete polymerization at $10,7.5$, and $5.0 \mathrm{~mol} \%$ catalyst loadings. There was little impact of the substituents on the aryl ring of the sulfenate anion $\left(\mathrm{ArSO}^{-}\right)$, with similar $M_{\mathrm{n}}$ and polydispersity index (PDI) $\left(M_{\mathrm{n}} \sim 10,000\right.$ were observed at 10 and $7.5 \mathrm{~mol} \%$ loading and $M_{\mathrm{n}} \sim 9000$ at $5.0 \mathrm{~mol} \%$ loading). Lower catalyst loadings of $2.5 \mathrm{~mol} \%$ led to oligomerization (see Supplementary Table 1). Moreover, we observed complete consumption of monomer $\mathbf{M 1}$ after $10 \mathrm{~min}$. A rapid loss of monomer at the beginning of the polymerization indicates that the BCCP proceeds by a step-growth mechanism.

At this stage of our investigations we chose to employ precatalyst 10. Under the basic conditions of the polymerization, 10 rapidly undergoes E2 elimination to form styrene and generate the sulfenate anion ${ }^{12}$. The most promising results with precatalyst 10 were with $7.5 \mathrm{~mol} \%\left(M_{\mathrm{n}} 10,900\right.$, PDI 1.26). At this loading, we conducted a second screen focused on 10 bases [ $\mathrm{LiO} t \mathrm{Bu}, \mathrm{NaO} t \mathrm{Bu}$, $\mathrm{LiN}\left(\mathrm{SiMe}_{3}\right)_{2}, \mathrm{NaN}\left(\mathrm{SiMe}_{3}\right)_{2}, \mathrm{KN}\left(\mathrm{SiMe}_{3}\right)_{2}, \mathrm{NaH}, \mathrm{KH}, \mathrm{KOSiMe}_{3}$, $\mathrm{KOPh}, \mathrm{NaOMe}]$ under otherwise identical conditions (Fig. 2b). Analysis of the resulting reactions indicated that polymer was obtained only with $\mathrm{LiN}\left(\mathrm{SiMe}_{3}\right)_{2}, \mathrm{NaN}\left(\mathrm{SiMe}_{3}\right)_{2}, \mathrm{KN}\left(\mathrm{SiMe}_{3}\right)_{2}$ with $M_{\mathrm{n}}$ all lower than with $\mathrm{KO} t \mathrm{Bu}$ from the first screen (see Supplementary Table 2).

The next step in the optimization was a solvent screen. We examined five solvents (THF, dioxane, MTBE (methyl tert-butyl ether), toluene, and dimethylformamide). As shown in Fig. 2C, the most promising result was obtained in MTBE $\left(M_{\mathrm{n}} 13,200\right.$, PDI 1.23).

After narrowing our optimization parameters to precatalyst 10 (7.5 mol \%), KOtBu, and CPME and MTBE as two top solvents, we conducted lab-scale $(0.1 \mathrm{mmol})$ polymerizations to validate the microscale results and further optimize the BCCP (Table 1). Lab-scale polycondensation of monomer M1 with both CPME and MTBE at $0.05 \mathrm{M}$ concentration yielded polymer with $M_{\mathrm{n}}$ 10,400 , PDI 1.28 in $91 \%$ isolated yield for CPME and polymer with $M_{\mathrm{n}}$ 13,600, PDI 1.21 in 69\% isolated yield with MTBE. The results confirmed that $M_{\mathrm{n}}$ and PDI of polymers obtained at 10 $\mu \mathrm{mol}$ scale could be reproduced at $0.1 \mathrm{mmol}$ scale. With CPME as solvent, increasing concentration to $0.1 \mathrm{M}$ and $0.2 \mathrm{M}$ (entries 3-4) led to higher $M_{\mathrm{n}}(11,200$ at $0.1 \mathrm{M}$ and 12,200 at $0.2 \mathrm{M})$ with

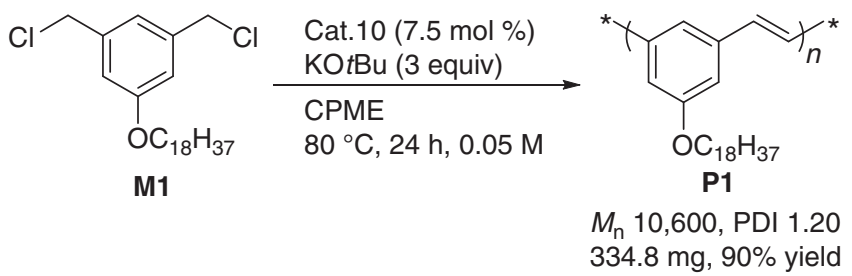

Fig. 3 Scale-up of $\mathbf{P 1}$. Synthesis of $\mathbf{P 1}$ by BCCP reaction

similar PDIs. The yields, however, dropped from 91\% $(0.05 \mathrm{M})$ to $86 \%(0.1 \mathrm{M})$ and $73 \%(0.2 \mathrm{M})$. With MTBE as solvent, increasing concentration led to higher $M_{\mathrm{n}}$ of $15,300(0.1 \mathrm{M}$, entry 5) in $72 \%$ yield and $17,400(0.2 \mathrm{M}$, entry 6$)$ in $71 \%$ yield, with PDI of the corresponding polymers of 1.41. Employing 4 and 5 equivalents of $\mathrm{KO} t \mathrm{Bu}$ afforded polymer product with similar $M_{\mathrm{n}}$, PDI, and yield (entries 7-8). The $M_{\mathrm{n}}$ dropped to 10,200 when 6 equiv. of base were employed (entry 9 ).

Scalability of BCCP with monomer M1. Scalability is an important attribute of polymerization catalysts. We next scaled the BCCP of M1 to $1 \mathrm{mmol}$ scale using the conditions outlined in Table 1, entry 1. Under the reaction conditions shown in Fig. 3, the polymer P1 was obtained with $M_{\mathrm{n}}$ 10,600 and PDI 1.20 in $90 \%$ yield $(334.8 \mathrm{mg})$.

Mechanistic distinctness of BCCP. Traditionally, PPVs were synthesized by a two-step quinodimethane polymerization/elimination protocol (the precursor route) ${ }^{19}$. The quinodimethane polymerization forms a non-conjugated polymer that is then converted to the conjugated PPV by high-temperature (180-300 ${ }^{\circ} \mathrm{C}$ ) thermal elimination reaction (Fig. $\left.4 \mathrm{a}\right)^{49}$. The harsh conditions required for converting non-conjugated precursor polymers to PPVs and the incomplete elimination lead to structural defects, which affect the luminescence quantum efficiency of the PPV films $s^{50}$. In sharp contrast, sulfenate anion-catalyzed BCCP proceeds by a different mechanism, which results in chemoselective construction of trans double bonds (Fig. 4b). Compared with other common methods for the preparation of PPVs such as transition metal-mediated Heck reactions, cross-coupling reactions, and metathesis reactions ${ }^{51}$, BCCP is a transition metal-free process.

To highlight the advantage of BCCP over precursor routes (Gilch, Wesling, and Vanderzande methods) (Fig. 4a), we designed monomer $\mathbf{M} 2$ in which two benzyl chloromethyl groups are linked by a $\mathrm{C}\left(\mathrm{CF}_{3}\right)_{2}$ bridge (Fig. 5). As the $\mathrm{C}\left(\mathrm{CF}_{3}\right)_{2}$ linker prevents the formation of quinodimethane intermediate, polymer P2 could not be prepared by precursor routes (Fig. 4a). Using the conditions in Table 1 (entry 1), the BCCP afforded polymer P2 in $82 \%$ yield with $M_{\mathrm{n}} 14,300$ and PDI 1.45 .

Synthesis and characterization of alternating 1,3- and 1,4linked copolymers. It is well-known that OLED device performance is greatly influenced by the structural regularity of the polymers. To further demonstrate the synthetic potential of BCCP, we next employed BCCP in the synthesis of challenging alternating copolymers. We designed a class of monomers (M3, Fig. 6a) by incorporating a flourenyl group between two metaphenyl groups. Polymerization of monomer M3 bearing different central Ar groups is expected to lead to a new class of structurally regular and alternating poly[(1,3-phenylene vinylene)-alt-arene]s. As proof-of-concept, we synthesized a fluorine-containing monomer M3-1. BCCP of M3-1 led to co-polymer P3-1 in 91\% yield with $M_{\mathrm{n}}$ 13,000 and PDI 2.00 (see Supplementary Method, 


\section{a Precursor route}

Step 1. Quinodimethane polymerization<smiles>[X]Cc1ccc(C[Y])c(CCCCC)c1</smiles>

Quinodimethane intermediate

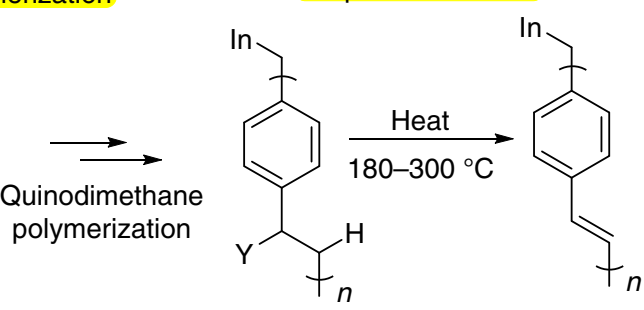

Precursor polymer

Wesling: $\mathrm{X}, \mathrm{Y}=\mathrm{SR}_{2}$

Vanderzande: $\mathrm{X}=\mathrm{Cl}, \mathrm{Y}=\mathrm{SOR}$

Gilch: $\mathrm{X}, \mathrm{Y}=\mathrm{Cl}, \mathrm{Br}$

b $\mathrm{BCCP}$

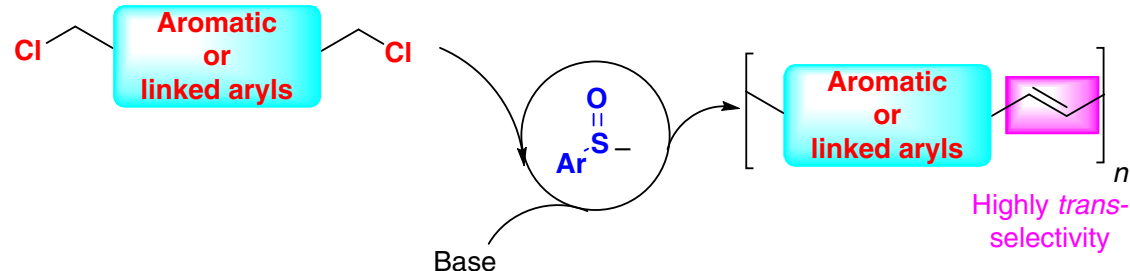

Fig. 4 Comparison of BCCP polymerization with precursor routes. a Summary of precursor route. $\mathbf{b}$ BCCP polymerization

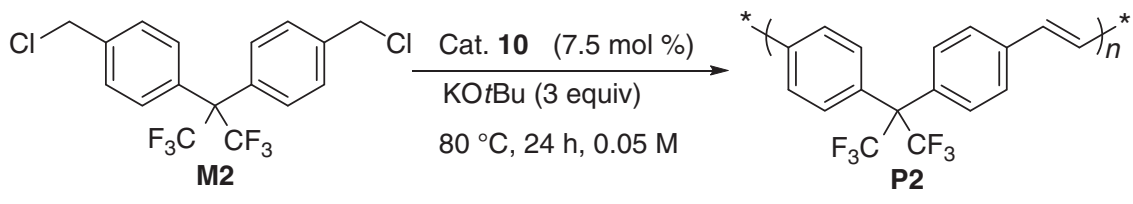

$82 \%$ yield, $M_{\mathrm{n}} 14,300$, PDI 1.45

Fig. 5 Synthesis of polymer P2. The polymer generated has a $\mathrm{C}\left(\mathrm{CF}_{3}\right)_{2}$ linker

$1 \mathrm{mmol}$ Scale synthesis and characterization of co-polymer P3-1, P4-1, for the synthesis of monomer M3-1 and co-polymer P4-1).

Previous studies have shown that $\left(\mathrm{P}^{m} \mathrm{PV} P \mathrm{PV}\right)$ s are highly photoluminescent polymers with well-defined conjugation lengths ${ }^{52-55}$. Such observations inspired us to design a member of this class, monomer M4. We expect that polymerization of M4 type monomers will achieve the synthesis of structurally regular $\left(\mathrm{P}^{m} \mathrm{PV} P \mathrm{PV}\right)$ s with $1: 1$ alternating ${ }^{m} \mathrm{PV}$ and $P \mathrm{PV}$ units along the chain linked by trans $\mathrm{C}=\mathrm{C}$ bonds (Fig. 6b). Moreover, incorporation of different moieties as side-chains into the $\mathrm{P}^{m} \mathrm{PV}^{p} \mathrm{PV}$ backbone ( $\mathrm{R}$ group on the $P \mathrm{PV}$ unit of $\mathrm{P} 4$ ), would allow tuning of the emission wavelength, emission color and change the quantum efficiency of the resulting co-polymer P4. As a proof-of-concept, we synthesized a thiophene-containing monomer M4-1. BCCP of M4-1 led to co-polymer P4-1 in 93\% yield with $M_{\mathrm{n}} 8000$ and PDI 1.82 (see Supplementary Method, $1 \mathrm{mmol}$ Scale synthesis and characterization of co-polymer P3-1, P4-1, for the synthesis of monomer M4-1 and co-polymer P4-1). Notably, both polymers P3-1 and P4-1 are not accessible by the precursor route, demonstrating the value of BCCP in co-polymer synthesis.

The thermal, photophysical, electrochemical and charge transport properties of P3-1 and P4-1 were characterized (see Supplementary Figure 37). As shown in Fig. 7a, I, the decomposition temperatures $\left(T_{\mathrm{d}}\right.$, corresponding to $5 \%$ weight loss) measured from thermogravimetric analysis were $420^{\circ} \mathrm{C}$ and $404^{\circ} \mathrm{C}$ for P3-1 and P4-1, respectively, indicating good thermal stability. Thermal stability is valuable for long device operation in emission materials ${ }^{15}$. From the glass transition temperatures $\left(T_{\mathrm{g}}\right)$ observed from differential scanning calorimetry (DSC) for the more rigid fluorene containing P3-1 was $141^{\circ} \mathrm{C}$; however, no obvious phase transition temperature could be obtained for P4-1 with more flexible $\mathrm{C}-\mathrm{C}$ double bonds in the conjugated backbone (Fig. 7b). Both polymers showed bright emission under UV excitation, as shown in the photo images of Fig. 7c,d, II. From the UV-Vis spectra in both solution and film (Fig. 7c,d), it is found that two-dimensional conjugated P4-1 with the pendant thiophene ring exhibited broader and red-shifted absorption relative to P3-1, with a one-dimensional conjugated polymer backbone. Regarding the photoluminescence (PL), the thiophenecontaining P4-1 displayed red-shifted PL compared with P3-1, with emission peaks in the deep blue ( $435 \mathrm{~nm}$ in THF and $457 \mathrm{~nm}$ in the film state) for P4-1 and ultra-violet (373 nm in THF and $402 \mathrm{~nm}$ in the film state) for P3-1. The electrochemical properties were measured by cyclic voltammetry (Fig. 7e). Both polymers exhibited quasi-reversible oxidation and irreversible reduction behavior. The highest occupied molecular orbital (HOMO) and lowest unoccupied molecular orbital (LUMO) energy levels were 
a Poly[(1,3-phenylene vinylene)-alt-arene]s

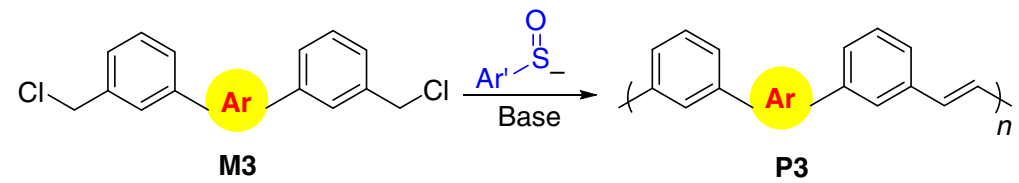

Ar = Fluorene:<smiles>CC(C)=Cc1cccc(-c2ccc3c(c2)C(C)(C)c2cc(-c4cccc(C)c4)ccc2-3)c1</smiles>

b Poly[(1,3-phenylene vinylene)-alt-(1,4-phenylene vinylene)]

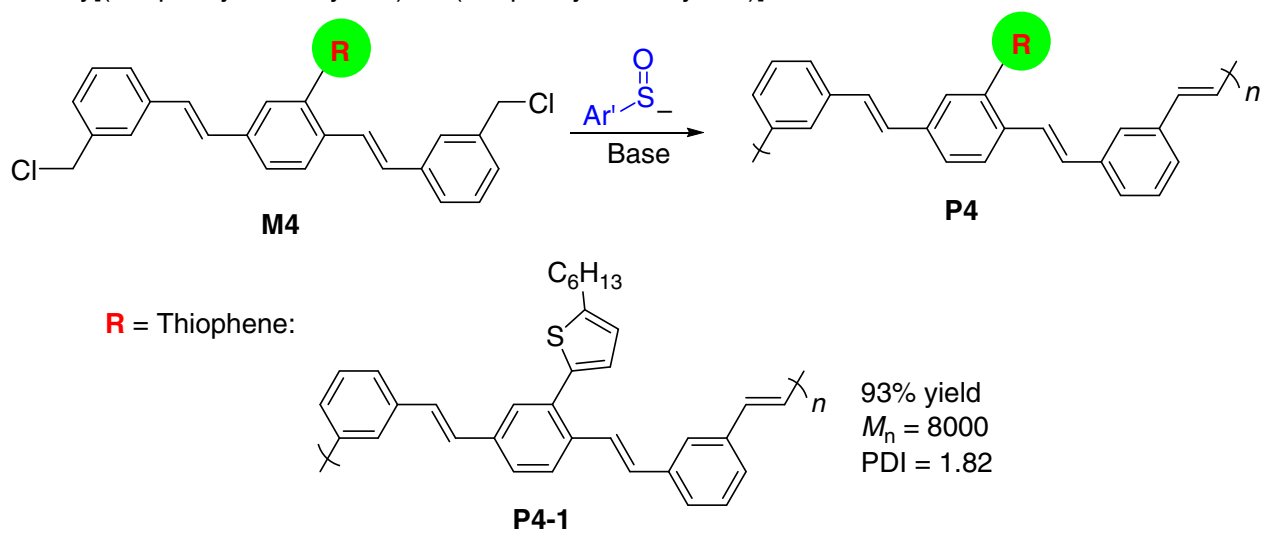

Fig. 6 Design and synthesis of alternating co-polymers. a Poly[(1,3-phenylene vinylene)-alt-arene]s. b Poly[(1,3-phenylene vinylene)-alt-(1,4-phenylene vinylene)] ( $\left.P^{m} P^{P} P V\right) s$

determined from the onset of oxidation and reduction curves for P3-1 and P4-1, and were calculated to be $-5.97 /-2.60 \mathrm{eV}$ and $-5.65 /-2.77 \mathrm{eV}$, respectively. Compared with P3-1, the introduction of a strong electron-donating thiophene ring in P4-1 significantly raises the $\mathrm{HOMO}$ level by $0.32 \mathrm{eV}$, suggesting a more efficient hole-injection and better hole transport properties of P4$\mathbf{1}$ in optoelectronic devices. This prediction is in good agreement with the measured hole mobility from the space charge limited current method (Fig. 7f). The hole mobility for the thiophenecontaining P4-1 is estimated to be $1.56 \times 10^{-6} \mathrm{~cm}^{2} \mathrm{~V}^{-1} \mathrm{~s}^{-1}$, which doubles P3-1 of $7.79 \times 10^{-7} \mathrm{~cm}^{2} \mathrm{~V}^{-1} \mathrm{~s}^{-1}$.

\section{Discussion}

Introduced herein is a class of organocatalytic polymerization processes termed BCCP. The organocatalysts for this process, sulfenate anions, are operationally trivial to generate from benchstable sulfoxide precatalysts in the presence of base. Sulfenate anion organocatalysts are unique in that they enable generation of $\mathrm{C}=\mathrm{C}$ double bonds of the type found in PPV's and other stilbenebased polymers. We demonstrated the application of sulfenate anion-catalyzed transfer polycondensation methods to polymers bearing isolated stilbene motifs. The important conceptual advance of this work is that it suggests that small organic molecules that can activate substrates via nucleophilic attack, acidify neighboring hydrogens leading to umpolung reactivity, and then behave as leaving groups can be considered in polymerization processes to forge $\mathrm{C}=\mathrm{C}$ linkages. From the synthetic aspect, BCCP offers transition metal-free access to wide varieties of polymers that cannot be synthesized by traditional precursor routes (Gilch, Wesling, and Vanderzande methods). To further demonstrate the synthetic potential of BCCP, two alternating copolymers were synthesized as representatives of classes of poly [(1,3-phenylene vinylene)-alt-arene $] s$ and $\left(\mathrm{P}^{m} \mathrm{PV}^{p} \mathrm{PV}\right) \mathrm{s}$. NMR spectra, thermal, photophysical, electrochemical, and charge transport properties of the above mentioned polymers were characterized. Further studies are underway to apply BCCP to the preparation of novel functionalized polymers.

\section{Methods}

General procedure for the $\mathbf{0 . 1} \mathbf{~ m m o l ~ B C C P}$. An oven-dried $8 \mathrm{~mL}$ microwave vial equipped with a stir bar was charged with monomer M1 (44.4 mg, $0.10 \mathrm{mmol}$ ) under a nitrogen atmosphere in a glove box. A solution of precatalyst $10(1.73 \mathrm{mg}$, $0.0075 \mathrm{mmol}$ ) in $1.0 \mathrm{~mL}$ anhydrous CPME was added by syringe. Next, a solution of $\mathrm{KO} t \mathrm{Bu}(33.6 \mathrm{mg}, 0.30 \mathrm{mmol})$ in $1.0 \mathrm{~mL}$ anhydrous CPME was added by syringe. The reaction was stirred for $24 \mathrm{~h}$ at $80^{\circ} \mathrm{C}$, quenched with 2 drops of $\mathrm{H}_{2} \mathrm{O}$ via syringe, cooled to room temperature, and opened to air. After the volatile materials were removed with a rotary evaporator, $\mathrm{CHCl}_{3}(2 \mathrm{~mL})$ was added into each vial and the slurry solution was allowed to stir for $10 \mathrm{~min}$. Cold methanol $(6 \mathrm{~mL})$ and $\mathrm{H}_{2} \mathrm{O}$ $(0.5 \mathrm{~mL})$ was then added into each vial to precipitate the polymer and the slurry solution with polymer suspension was allowed to stir for $10 \mathrm{~min}$. The mixture was then transferred with a pipette onto a Whatman autovial syringeless filter $(5 \mathrm{~mL}$, $0.45 \mu \mathrm{m}$ polytetrafluoroethylene (PTFE) membrane). After the $\mathrm{MeOH} / \mathrm{CHCl}_{3} / \mathrm{H}_{2} \mathrm{O}$ solution was filtered, polymer that remained in the filter was washed sequentially with $5 \mathrm{~mL} \mathrm{MeOH}$ and $5 \mathrm{~mL}$ pentane. Finally, the polymer remaining in the filter was transferred into a $20 \mathrm{~mL}$ vial with spatula and dried under vacuum to yield a pale yellow solid in $33.8 \mathrm{mg}$, $91 \%$ yield.

General procedure for the scale-up $(1 \mathrm{mmol})$ polymerization. An oven-dried $100 \mathrm{~mL}$ Schlenk tube equipped with a stir bar was charged with monomer 1 (444.0 $\mathrm{mg}, 1.0 \mathrm{mmol})$ and precatalyst $10(17.3 \mathrm{mg}, 0.075 \mathrm{mmol})$. The Schlenk tube was sealed with a rubber septum and was connected to a Schlenk line, evacuated, and refilled with nitrogen (repeated three times). Next, a solution of KOtBu (336 mg, 


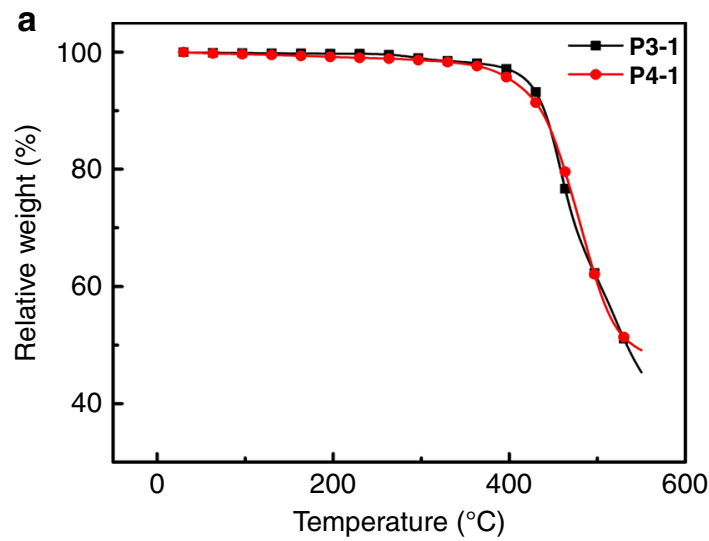

b

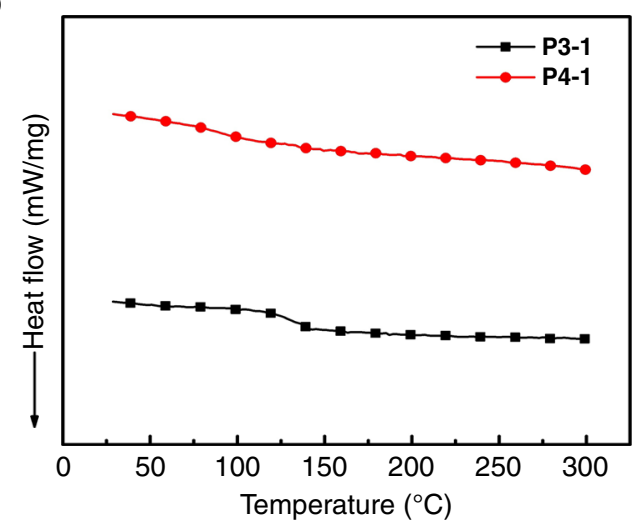

d
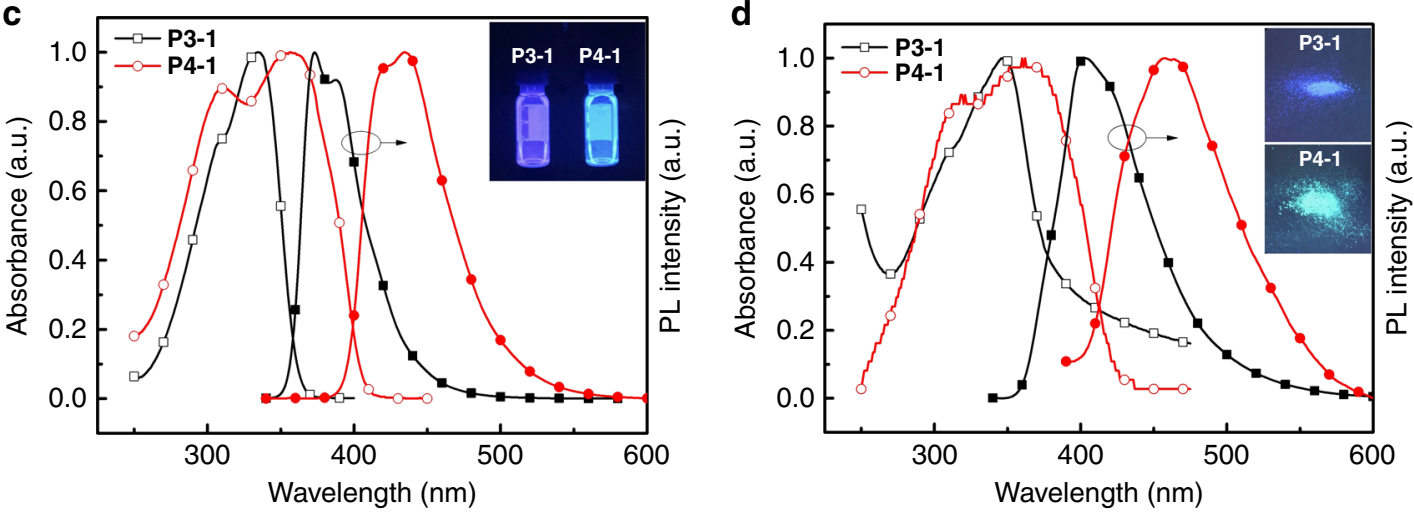

e

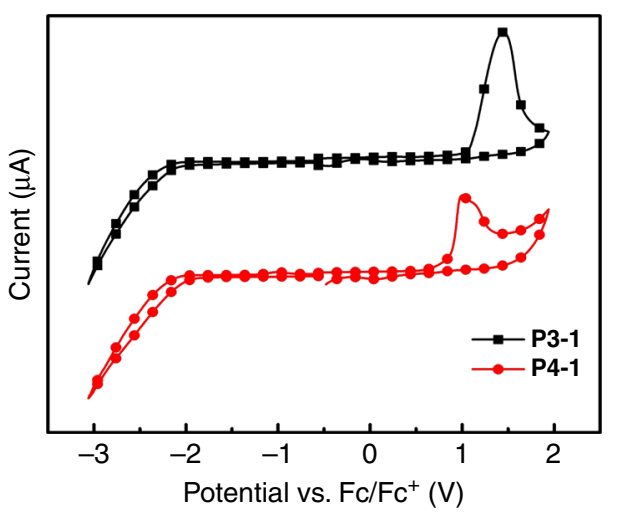

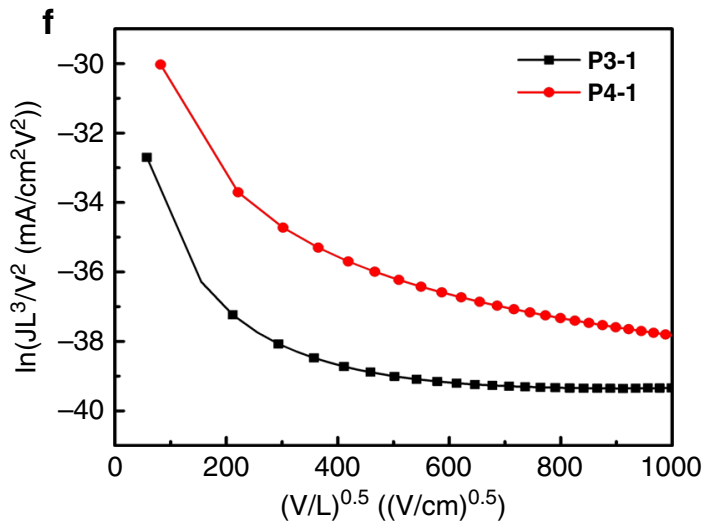

Fig. 7 Polymer characterization. a TGA curves of the co-polymers P3-1 and P4-1. b DSC curves of the co-polymers P3-1 and P4-1. c Normalized UV-Vis absorption and PL spectra of co-polymers P3-1 and P4-1 in THF solution and photographs of polymer photoluminescence under $365 \mathrm{~nm}$ light in THF solution. d Normalized UV-Vis absorption and PL spectra of co-polymers P3-1 and P4-1 in film state and photographs of polymer photoluminescence under $365 \mathrm{~nm}$ light in solid state. e Cyclic voltammograms of the oxidation curves in dichloromethane and reduction curves in THF for co-polymers P3-1 and P41. $\mathbf{f}$ Current density-voltage $(J-V)$ characteristics of hole-only devices with structure of ITO/PEDOT:PSS $(30 \mathrm{~nm}) / \mathbf{P 3 - 1} \mathrm{or} \mathbf{P 4 - 1}(30 \mathrm{~nm}) / \mathrm{MoO}_{3}(8 \mathrm{~nm}) / \mathrm{Ag}$

$3.0 \mathrm{mmol}$ ) in $20 \mathrm{~mL}$ anhydrous CPME was added by syringe. The reaction was stirred for $24 \mathrm{~h}$ at $80^{\circ} \mathrm{C}$, cooled to room temperature, opened to air, and quenched with $1 \mathrm{~mL}$ of $\mathrm{H}_{2} \mathrm{O}$. The reaction mixture was firstly transferred to a $250 \mathrm{~mL}$ roundbottom flask and the volatile materials were removed with a rotary evaporator. Next, $\mathrm{CHCl}_{3}(20 \mathrm{~mL})$ was added into flask and the slurry solution was allowed to stir for $10 \mathrm{~min}$. Cold methanol $(60 \mathrm{~mL})$ was added into the flask to precipitate the polymer and the slurry solution with polymer suspension was allowed to stir for 10 $\mathrm{min}$. The mixture was then filtered on a glass fritted filter funnel $(75 \mathrm{~mL})$. After the $\mathrm{MeOH} / \mathrm{CHCl}_{3}$ solution was filtered, the resulting solid was washed with $\mathrm{H}_{2} \mathrm{O}(5$ $\mathrm{mL}), \mathrm{MeOH}\left(20 \mathrm{~mL}^{*} 3\right)$, and pentane $(5 \mathrm{~mL})$. The solid was collected and dried in a vacuum as pale yellow solid to provide $334.8 \mathrm{mg}$, $90 \%$ yield of the polymer.

Data availability. The authors declare that the data supporting the findings of this study are available within the article and its Supplementary Information files.
Received: 19 May 2017 Accepted: 3 April 2018

Published online: 01 May 2018

\section{References}

1. Ober, C. K. et al. Research in macromolecular science: challenges and opportunities for the next decade. Macromolecules 42, 465-471 (2009).

2. Hawker, C. J. \& Wooley, K. L. The convergence of synthetic organic and polymer chemistries. Science 309, 1200-1205 (2005).

3. Kiesewetter, M. K., Shin, E. J., Hedrick, J. L. \& Waymouth, R. M. Organocatalysis: opportunities and challenges for polymer synthesis. Macromolecules 43, 2093-2107 (2010). 
4. Ottou, W. N., Sardon, H., Mecerreyes, D., Vignolle, J. \& Taton, D. Update and challenges in organo-mediated polymerization reactions. Prog. Polym. Sci. 56, 64-115 (2016).

5. Hong, M. \& Chen, E. Y. Proton-transfer polymerization (HTP): converting methacrylates to polyesters by an N-heterocyclic carbene. Angew. Chem. 53, 11900-11906 (2014).

6. Hong, M. et al. Proton-transfer polymerization by N-heterocyclic carbenes: monomer and catalyst scopes and mechanism for converting dimethacrylates into unsaturated polyesters. J. Am. Chem. Soc. 138, 2021-2035 (2016).

7. Maitro, G. et al. Enantioselective synthesis of aryl sulfoxides via palladiumcatalyzed arylation of sulfenate anions. Org. Lett. 9, 5493-5496 (2007).

8. O'Donnell, J. S. \& Schwan, A. L. Generation, structure and reactions of sulfenic acid anions. J. Sulfur Chem. 25, 183-211 (2004).

9. Schwan, A. L. \& Söderman, S. C. Discoveries in sulfenic acid anion chemistry. Phosphorus Sulfur. Silicon Relat. Elem. 188, 275-286 (2013).

10. Soderman, S. C. \& Schwan, A. L. Sulfenate substitution as a complement and alternative to sulfoxidation in the diastereoselective preparation of chiral beta-substituted beta-amino sulfoxides. J. Org. Chem. 78, 1638-1649 (2013).

11. Zhang, M. et al. A new class of organocatalysts: sulfenate anions. Angew. Chem. Int. Ed. Engl. 53, 10755-10758 (2014).

12. Zhang, M., Jia, T., Wang, C. Y. \& Walsh, P. J. Organocatalytic synthesis of alkynes. J. Am. Chem. Soc. 137, 10346-10350 (2015).

13. Wang, S. et al. A DRIFTS study of low-temperature CO oxidation over $\mathrm{Au} / \mathrm{SnO}_{2}$ catalyst prepared by co-precipitation method. Catal. Commun. 10, 640-644 (2009).

14. Cheng, Y. J., Yang, S. H. \& Hsu, C. S. Synthesis of conjugated polymers for organic solar cell applications. Chem. Rev. 109, 5868-5923 (2009).

15. Gunes, S., Neugebauer, H. \& Sariciftci, N. S. Conjugated polymer-based organic solar cells. Chem. Rev. 107, 1324-1338 (2007).

16. Wang, S. et al. Porous ceria hollow microspheres: synthesis and characterization. Microporous Mesoporous Mater. 123, 349-353 (2009).

17. Spanggaard, H. \& Krebs, F. C. A brief history of the development of organic and polymeric photovoltaics. Sol. Energ. Mat. Sol. Cells 83, 125-146 (2004).

18. Grimsdale, A. C., Chan, K. L., Martin, R. E., Jokisz, P. G. \& Holmes, A. B. Synthesis of light-emitting conjugated polymers for applications in electroluminescent devices. Chem. Rev. 109, 897-1091 (2009).

19. Junkers, T., Vandenbergh, J., Adriaensens, P., Lutsen, L. \& Vanderzande, D. Synthesis of poly(p-phenylene vinylene) materials via the precursor routes. Polym. Chem. 3, 275-285 (2012).

20. Becker, H., Spreitzer, H., Ibrom, K. \& Kreuder, W. New insights into the microstructure of GILCH-polymerized PPVs. Macromolecules 32, 4925-4932 (1999).

21. Gilch, H. G. \& Wheelwright, W. L. Polymerization of $\alpha$-halogenated p-xylenes with base. J. Polym. Sci. A Polym. Chem. 4, 1337-1349 (1966).

22. Ravnsbæk, J. B. \& Swager, T. M. Mechanochemical synthesis of poly (phenylene vinylenes). ACS Macro. Lett. 3, 305-309 (2014).

23. Zaquen, N., Lutsen, L., Vanderzande, D. \& Junkers, T. Controlled/living polymerization towards functional poly(p-phenylene vinylene)materials. Polym. Chem. 7, 1355-1367 (2016).

24. McCullough, R. D. \& Lowe, R. D. Enhanced electrical conductivity in regioselectively synthesized poly(3-alkylthiophenes). J. Chem. Soc. Chem. Commun. 0, 70-72 (1992)

25. Lenz, R. W. \& Handlovits, C. E. Thermally stable hydrocarbon polymers: polyterephthalylidenes. J. Org. Chem. 25, 813-817 (1960).

26. Suzuki, Y., Hashimoto, K. \& Tajima, K. Synthesis of regioregular poly(pphenylenevinylene)s by Horner reaction and their regioregularity characterization. Macromolecules 40, 6521-6528 (2007).

27. Schenk, R., Gregorius, H., Meerholz, K., Heinze, J. \& Muellen, K. Novel oligo (phenylenevinylenes): models for the charging of extended.pi. chains. J. Am. Chem. Soc. 113, 2634-2647 (1991).

28. Yang, Z. \& Geise, H. J. Preparation and electrical conductivity of blends consisting of modified Wittig poly(para-phenylene vinylene), iodine and polystyrene, polymethyl methacrylate or polycarbonate. Synt. Met. 47, 105-109 (1992).

29. Conticello, V. P., Gin, D. L. \& Grubbs, R. H. Ring-opening metathesis polymerization of substituted bicyclo[2.2.2] octadienes: a new precursor route to poly(1,4-phenylenevinylene). J. Am. Chem. Soc. 114, 9708-9710 (1992).

30. Zou, Y., Hou, J., Yang, C. \& Li, Y. A novel n-type conjugated polymer DOCNPPV: synthesis, optical, and Eeectrochemical properties. Macromolecules 39, 8889-8891 (2006).

31. Schneider, J. A., Dadvand, A., Wen, W. \& Perepichka, D. F. Tuning the electronic properties of poly(thienothiophene vinylene)s via alkylsulfanyl and alkylsulfonyl substituents. Macromolecules 46, 9231-9239 (2013).
32. Bao, Z., Chan, W. K. \& Yu, L. Exploration of the Stille coupling reaction for the synthesis of functional polymers. J. Am. Chem. Soc. 117, 12426-12435 (1995).

33. Wakioka, M., Ikegami, M. \& Ozawa, F. Stereocontrolled synthesis and photoisomerization behavior of all-cis and all-trans poly(mphenylenevinylene)s. Macromolecules 43, 6980-6985 (2010).

34. Katayama, H. et al. Stereocontrolled synthesis and characterization of cis-poly (arylenevinylene)s. Macromolecules 39, 2039-2048 (2006).

35. Katayama, H. et al. Stereocontrolled synthesis and optical properties of all-cis poly(phenylene vinylenes) (PPVs): a method for direct patterning of PPVs. J. Am. Chem. Soc. 127, 4350-4353 (2005).

36. Yu, L., Lee, Y. \& Liang, Y. The Heck polycondensation for functional polymers. Synlett 2006, 2879-2893 (2006)

37. Cyriac, A., Amrutha, S. R. \& Jayakannan, M. Renewable resource-based poly (m-phenylenevinylene)s and their statistical copolymers: synthesis, characterization, and probing of molecular aggregation and Forster energy transfer processes. J. Polym. Sci. A Polym. Chem. 46, 3241-3256 (2008).

38. Drury, A. et al. Systematic trends in the synthesis of (meta-phenylene vinylene) copolymers. Synth. Met. 119, 151-152 (2001).

39. Liao, L., Pang, Y., Ding, L. \& Karasz, F. E. Blue-emitting soluble poly(mphenylenevinylene) derivatives. Macromolecules 34, 7300-7305 (2001).

40. Liao, L., Pang, Y., Ding, L. \& Karasz, F. E. Synthesis, characterization and luminescence of poly[(m-phenylenevinylene)-alt-(1,4-dibutoxy-2,5phenylenevinylene)] with different content of cis- and trans-Olefins. Macromolecules 34, 6756-6760 (2001).

41. Zhang, H., Marin, V., Fijten, M. W. M. \& Schubert, U. S. High-throughput experimentation in atom transfer radical polymerization: a general approach toward a directed design and understanding of optimal catalytic systems. $J$. Polym. Sci. A Polym. Chem. 42, 1876-1885 (2004).

42. Potyrailo, R. et al. Combinatorial and high-throughput screening of materials libraries: review of state of the art. ACS Comb. Sci. 13, 579-633 (2011).

43. Li, M. et al. Transition-metal-free radical $\mathrm{C}(\mathrm{sp}(3))-\mathrm{C}(\mathrm{sp}(2))$ and $\mathrm{C}(\mathrm{sp}(3))-\mathrm{C}(\mathrm{sp}$ (3)) coupling enabled by 2-Azaallyls as super-electron-donors and couplingpartners. J. Am. Chem. Soc. 139, 16327-16333 (2017). For High-throughput screening in small molecule synthesis.

44. Li, M., Berritt, S. \& Walsh, P. J. Palladium-catalyzed regioselective arylation of 1,1,3-triaryl-2-azaallyl anions with aryl chlorides. Org. Lett. 16, 4312-4315 (2014).

45. Li, M. et al. Palladium-catalyzed $\mathrm{C}-\mathrm{H}$ arylation of $\alpha, \beta$-unsaturated imines: catalyst-controlled synthesis of enamine and allylic amine derivatives. Angew. Chem. Int. Ed. 55, 2825-2829 (2016).

46. Li, M. et al. Transition-metal-free chemo- and regioselective vinylation of azaallyls. Nat. Chem. 9, 997-1004 (2017).

47. Li, M., Yucel, B., Adrio, J., Bellomo, A. \& Walsh, P. J. Synthesis of diarylmethylamines via palladium-catalyzed regioselective arylation of 1,1,3triaryl-2-azaallyl anions. Chem. Sci. 5, 2383-2391 (2014).

48. $\mathrm{Li}, \mathrm{M}$. et al. Umpolung synthesis of diarylmethylamines via palladiumcatalyzed arylation of N-benzyl aldimines. Adv. Synth. Catal. 358, 1910-1915 (2016).

49. van Breemen, A. J. J. M. et al. Optimization of the polymerization process of sulfinyl precursor polymers toward poly(p-phenylenevinylene). Macromolecules 32, 5728-5735 (1999). For High-throughput screening in macromolecule synthesis.

50. Anuragudom, P., Newaz, S. S., Phanichphant, S. \& Lee, T. R. Facile Horner -Emmons synthesis of defect-free poly(9,9-dialkylfluorenyl-2,7-vinylene). Macromolecules 39, 3494-3499 (2006).

51. Babudri, F., Farinola, G. M. \& Naso, F. Synthesis of conjugated oligomers and polymers: the organometallic way. J. Mater. Chem. 14, 11-34 (2004).

52. Liao, L., Cirpan, A., Ding, L., Karasz, F. E. \& Pang, Y. Efficient blue-greenemitting poly[(5-diphenylamino-1,3-phenylenevinylene)-alt-(2,5-dihexyloxy1,4-phenylenevinylene)] derivatives: synthesis and optical properties. J. Polym. Sci. A. 44, 2307-2315 (2006).

53. Yang, L. J. et al. Host-guest system of hesperetin and beta-cyclodextrin or it derivatives: preparation, characterization, inclusion mode, solubilization and stability. Mater. Sci. Eng. C. Mater. Biol. Appl. 59, 1016-1024 (2016).

54. Yang, L.-J. et al. Host-guest interaction between brazilin and hydroxypropyl$\beta$-cyclodextrin: preparation, inclusion mode, molecular modelling and characterization. Dyes Pigm. 150, 193-201 (2018).

55. Yang, L.-J. et al. Supramolecular system of podophyllotoxin and hydroxypropyl- $\beta$-cyclodextrin: characterization, inclusion mode, docking calculation, solubilization, stability and cytotoxic activity. Mater. Sci. Eng. C. 76, 1136-1145 (2017).

\section{Acknowledgements}

P.J.W. thanks the National Science Foundation (CHE-1464744). We thank Professor Jeung Gon Kim of Chonbuk National University and Dr. Jerome Robinson of UPenn for 
helpful discussions. C.W. thanks the Vagelos Integrated Program in Energy Research for funding and support.

\section{Author contributions}

P.J.W. conceived of the project. M.L and P.J.W. designed the experiments and monomers. M.L., S.B., C.W., X.Y., Y.L., S.-C.S., B.W., X.F., and R.W. performed the research. Z. L. conducted GPC analysis of co-polymers P3-1 and P4-1. X.G. and Y.T. performed the thermal, photophysical, electrochemical, and charge transport properties characterization. M.L. and P.J.W. wrote the paper.

\section{Additional information}

Supplementary Information accompanies this paper at https://doi.org/10.1038/s41467018-04095-x.

Competing interests: The authors declare no competing interests.

Reprints and permission information is available online at http://npg.nature.com/ reprintsandpermissions/
Publisher's note: Springer Nature remains neutral with regard to jurisdictional claims in published maps and institutional affiliations.

(c) (i) Open Access This article is licensed under a Creative Commons Attribution 4.0 International License, which permits use, sharing, adaptation, distribution and reproduction in any medium or format, as long as you give appropriate credit to the original author(s) and the source, provide a link to the Creative Commons license, and indicate if changes were made. The images or other third party material in this article are included in the article's Creative Commons license, unless indicated otherwise in a credit line to the material. If material is not included in the article's Creative Commons license and your intended use is not permitted by statutory regulation or exceeds the permitted use, you will need to obtain permission directly from the copyright holder. To view a copy of this license, visit http://creativecommons.org/ licenses/by/4.0/.

(C) The Author(s) 2018 